\title{
CRYSTALLIZATION KINETICS OF COMMERCIAL PLA FILAMENT
}

The Poly-Lactic Acid (PLA), the often used material for 3D printing and the rapid prototyping is very important in development process in automotive industry, as well. The commercial PLA filament was chosen and isothermal melt-crystallization and melting behavior was investigated by the DSC (differential scanning calorimetry). The PLA is a semi-crystalline biopolymer but the crystallization process is slow and sensitive to the changing of the cooling rate. Avrami equation was applied to analyze the crystallization. Arrhenius equation was used to calculate the activation energy and the equilibrium melting temperature was determined by the Hoffman-Weeks linear method. These results are the basis for further experiments.

Keywords: 3D printing, PLA, isothermal crystallization, DSC

\section{Introduction}

The rapid prototyping is an important part of product development process in several industry sector include automotive. There are more 3D printing technologies, and they have become popular and available. Besides the multinational and small companies, everyone as a private person, can buy a 3D printer and make own products. One of the frequently used 3D printing technology is the fused deposition modeling (FDM), which is based on the melt extrusion. The FDM is a layer by layer method built by melted thermoplastic fibers [1]. A lot of polymers are optional for printing but there is one special type-the Poly-Lactic Acid, the PLA.

The PLA is a biodegradable and compostable polymer produced from renewable resources, such as starch and sugar. The PLA is thermoplastic, semi-crystalline polyester and it is based on the lactic acid (LA), which can be produced by fermentation or chemical synthesis. There are two polymerization routes, one is polycondensation from the LA, and the other is the ring-opening polymerization from lactide, it is the dimer of the lactic acid. The LA has two stereoisomers L-lactic acid and D-lactic acid. The commercial PLA are copolymers of PLLA, poly (L-lactic acid) and PDLLA, poly (D, L-lactic acid), but the L-lactic is the main fraction. Depending on the copolymer ratio, properties, glass transition and the melting temperatures can be different.

Nowadays, the environmental protection is very important so the biopolymers as the PLA have become the center of interest. The elevated environmental awareness and the good properties (high tensile strength and Young's modulus, good flexural strength) have resulted in an expanded use of the PLA for consumer goods and packaging applications; furthermore it is expected that novel technological advances will lead to the biopolymers market boom in transportation and automotive industry [2-4].

Unfortunately, there are some drawbacks, for example the PLA is brittle material and the crystallization process is slow. The mechanical, thermal and optical properties, depend on the crystallinity, so investigating the crystallization is very important [2-4].

In this work, the isothermal melt-crystallization and melting behavior of a commercial 3D printing filament from the PLA was investigated. The Avrami equation was applied to analyze the crystallization kinetics. This study will be of the basis for the further experiments like nucleation, to improve crystallization and provide better mechanical properties.

\section{Experimental}

\subsection{Material}

The used PLA is a filament with $1.75 \mathrm{~mm}$ diameter and metallic blue color from Orbi-Tech GmbH. The Orbi-Tech Company gives only general information. There is no datasheet. We know only the diameter and the color.

\footnotetext{
* Adam Balazs

Department of Materials Technology, GAMF Faculty of Engineering and Computer Science, John von Neumann University, Hungary adam.balazs@gamf.uni-neumann.hu
} 


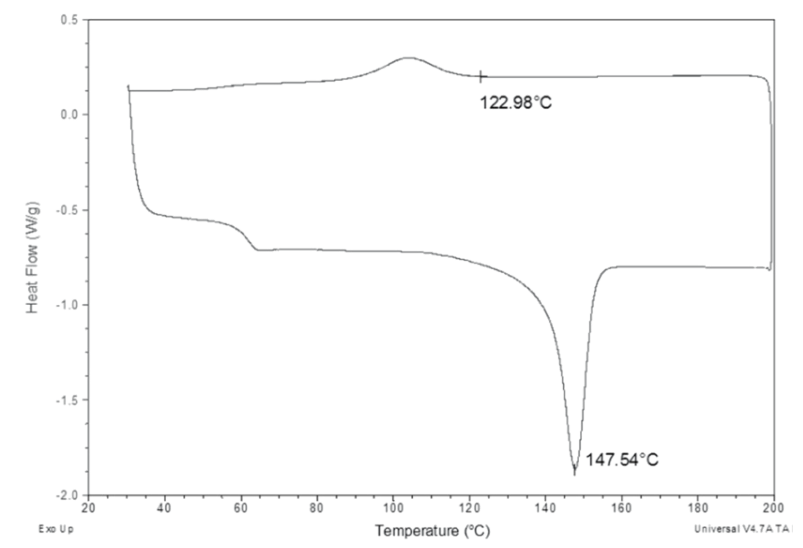

Figure 1 Heat - flow versus temperature, the starting temperature of crystallization and the melting peak temperature

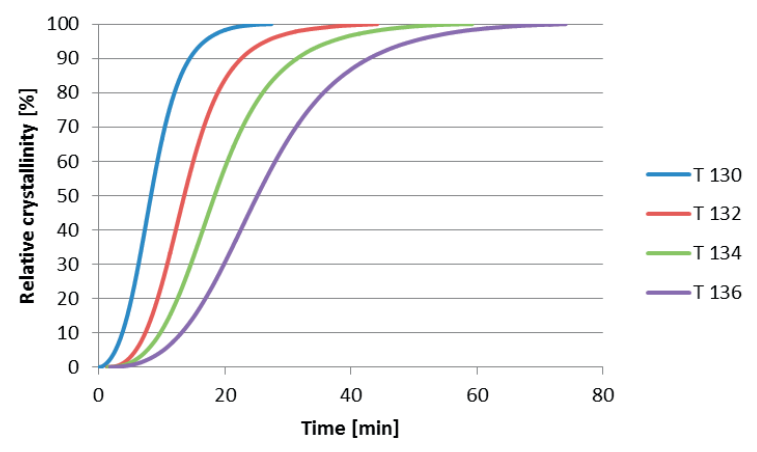

Figure 3 Relative crystallinity as a function of isothermal crystallization time

\subsection{Method}

The thermal behavior of the PLA was measured by differential scanning calorimeter (DSC), TA Q200 heat-flux DSC instrument, which was calibrated by Indium. The sample weight was $5.37 \mathrm{mg}$. The applied gas during the DSC scan was nitrogen; the using flowing rate was $50 \mathrm{ml} / \mathrm{min}$. The temperature range was from 30 ${ }^{\circ} \mathrm{C}$ to $200{ }^{\circ} \mathrm{C}$.

The first the sample was heated to $200{ }^{\circ} \mathrm{C}$ at a heating rate of $20^{\circ} \mathrm{C} / \mathrm{min}$ to eliminate any thermal history. Then the sample was cooled (by $5{ }^{\circ} \mathrm{C} / \mathrm{min}$ ) to the crystallization temperatures, which were $130,132,134$ and $136^{\circ} \mathrm{C}$. After the set time of crystallization, heating scan of $20^{\circ} \mathrm{C} / \mathrm{min}$ was used. This heating rate is too fast, so there is no time for recrystallization [5-8].

\section{Results and discussion}

Determination of temperatures and the holding times of the isothermal crystallization can be quite difficult. Prior to the isothermal measurements, it is necessary to perform an anisothermal scan (Figure 1) to determine the starting temperature of crystallization. The endotherm curve shows the

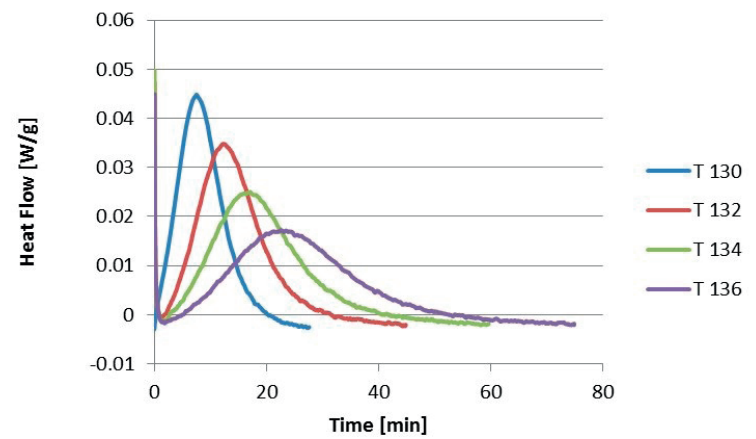

Figure 2 Heat-flow versus time during isothermal crystallization

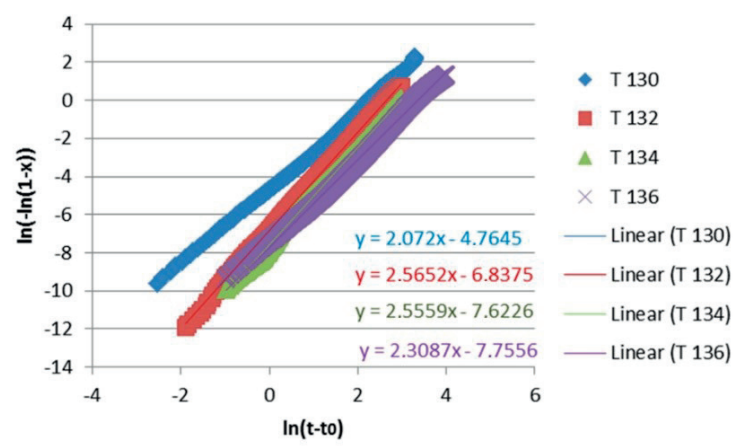

Figure 4 Straight lines obtained by the Avrami equation

melting, and the exotherm curve shows the crystallization. On the exotherm curve, when the line begin to change, it is the starting temperature of the crystallization.

The isotherm temperatures need to be higher than the start temperature of crystallization, but lower than the melting temperature. Several pre-tests were used to find the correct data, so in this work the first holding temperature was $130{ }^{\circ} \mathrm{C}$. The applied temperature step was $2{ }^{\circ} \mathrm{C}$ from 130 to $136{ }^{\circ} \mathrm{C}$.

Figure 2 shows the change of the heat flow versus isothermal crystallization time. The time zero $\left(\mathrm{t}_{0}\right)$ is that point when the real temperature reaches the setting temperature.

The asymmetrical shapes of the exothermic peaks suggest that the crystallization process presents some secondary crystallization. When the isothermal temperature was increased, the maximum of the heat flow was lower and the time of the crystallization was longer.

Figure 3 shows the relative crystallinity as a function of isothermal crystallization time.

The time to reach the end of the crystallinity increases with the increase of crystallization temperature. The change of the relative crystallinity with time can show the rate of the crystallization. The slope of the curve is reduced when the isothermal temperature increased and it means that the rate of the crystallization became lower. 
Table 1 Avrami exponent, rate constant and melting temperature versus crystallization temperature

\begin{tabular}{|c|c|c|c|c|}
\hline $\mathrm{T}_{\mathrm{c} \text { iso }}\left[{ }^{\circ} \mathrm{C}\right]$ & $\mathrm{T}_{\mathrm{c} \text { iso }}[1 / \mathrm{K}]$ & $\mathrm{n}$ & $\ln \mathrm{K}$ & $\mathrm{T}_{\mathrm{m}}\left[{ }^{\circ} \mathrm{C}\right]$ \\
\hline 130 & 0.00363343 & 2.072 & -4.765 & 155.31 \\
\hline 132 & 0.003626973 & 2.562 & -6.8375 & 156.71 \\
\hline 134 & 0.003627052 & 2.556 & -7.6226 & 158.11 \\
\hline 136 & 0.003630318 & 2.308 & -7.7556 & 159.22 \\
\hline
\end{tabular}

Table 2 Relationship between Avrami exponent and geometry of crystallite [9]

\begin{tabular}{cccc}
\hline Dimension & Geometry & $\mathrm{n}$ & \\
\cline { 3 - 4 } & & athermic nucleation & thermic nucleation \\
\hline 1 & Fibril (cylinder) & 1 & 2 \\
3 & Lamella (disk) & 3 & 4 \\
\hline
\end{tabular}

The Avrami equation (1) was used to analyze the increment of the relative crystallinity with time (Figure 3 ):

$$
x(t)=1-\exp \left(-K t^{n}\right)
$$

where $\mathrm{x}$ is the relative crystallinity, $\mathrm{K}$ is the rate constant of crystallization, $\mathrm{t}$ is the time and $\mathrm{n}$ is the Avrami exponent. The values $\mathrm{K}$ and $\mathrm{n}$ are considered to be diagnostic for the mechanism of crystallization [6-9].

After the relative crystallinity was transformed by the Avrami equation, almost the straight lines were obtained (Figure 4). The equation of the linear lines can show the Avrami exponent, which is the steepness and rate constant of the crystallization is the intersection of the $y$ axis.

Table 1 summarizes the result derived from the Avrami analysis and the melting peak temperatures after the isothermal crystallization. The heating rate was $20^{\circ} \mathrm{C} / \mathrm{min}$.

Table 1 Avrami exponent, rate constant and melting temperature versus crystallization temperature

The Avrami exponents were in the range of 2.1-2.6 for the temperature range of $130-136{ }^{\circ} \mathrm{C}$, suggesting a change in crystal growth from two to three dimensional with athermic nucleation. The rate constant is reduced as expected by increasing the isothermal crystallization temperature [4, 6-9].

The activation energy of the crystallization process was determined from the rates of crystallization by the Arrhenius equation (2):

$$
K=A \exp \left(-\frac{E_{a}}{R T}\right)
$$

where $\mathrm{K}$ is the rate of crystallization, $\mathrm{A}$ is a constant, $\mathrm{T}$ is the crystallization temperature, $\mathrm{R}$ is the universal gas constant and $\mathrm{E}_{\mathrm{a}}$ is the activation energy. The activation energy can be obtained from the slope of the plot of $\mathrm{K}$ as a function of reciprocal of crystallization temperature in Kelvin (Figure 5) [6-9].
The activation energy of this PLA is $670324.5 \mathrm{~J} / \mathrm{mol} \cdot \mathrm{K}$. The four points in Figure 5 are not collinear, so this activation energy is just an approximate value and further experiments are required.

After the isothermal crystallization, there were heating scans and the melting temperatures were measured. The applied heating rate was $20{ }^{\circ} \mathrm{C} / \mathrm{min}$. Figure 6 shows that if the isothermal crystallization temperature was higher, the melting peak temperature was higher too, because the crystallites became bigger and contain less mistakes [6-9].

The equilibrium melting temperature can be determined from the change of melting temperature. It is based on the linear method of Hoffman-Weeks (3):

$T_{m}=T_{m}^{0}\left(1-\frac{1}{\gamma}\right)+\frac{T_{c}}{\gamma}$

where $T_{m}$ is the melting temperature, $T_{m}{ }^{0}$ is the equilibrium melting temperature, $T_{c}$ is the crystallization temperature and $\gamma$ is the lamella thickening factor. The linear method means that it is assumed that there is no lamella thickening. The equilibrium melting temperature was determined by the relationship between the apparent melting temperature and the crystallization temperature. The plot of $\mathrm{T}_{\mathrm{m}}$ as function of $\mathrm{T}_{\mathrm{c}}$ gives straight lines whose intersection points with the line $T_{m}=T_{c}$ determine $T_{m}{ }^{0}$ (Figure 7) [5-9].

The equilibrium melting temperature of the PLA filament is $203.85^{\circ} \mathrm{C}$.

\section{Conclusion}

The commercial PLA filament was measured by the isothermal DSC method. The crystallization temperature range was between 130 and $136^{\circ} \mathrm{C}$ using $2{ }^{\circ} \mathrm{C}$ steps. The Avrami equation was applied to analyze the crystallization process. The Avrami exponent showed that the nucleation is athermic and the geometry can 


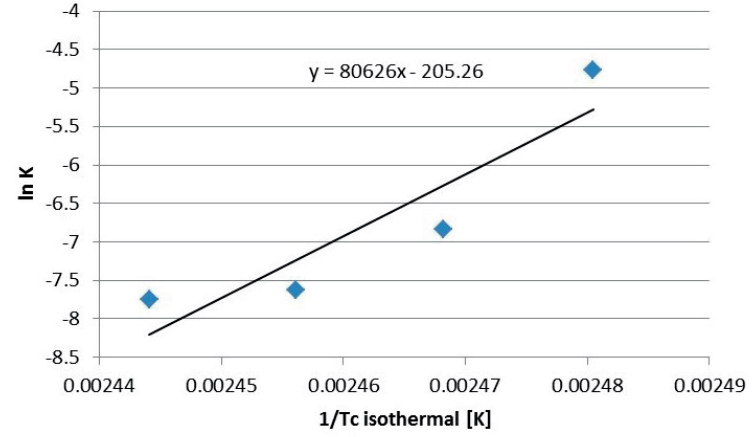

Figure 5 Rate constant versus reciprocal of isothermal crystallization temperature in Kelvin

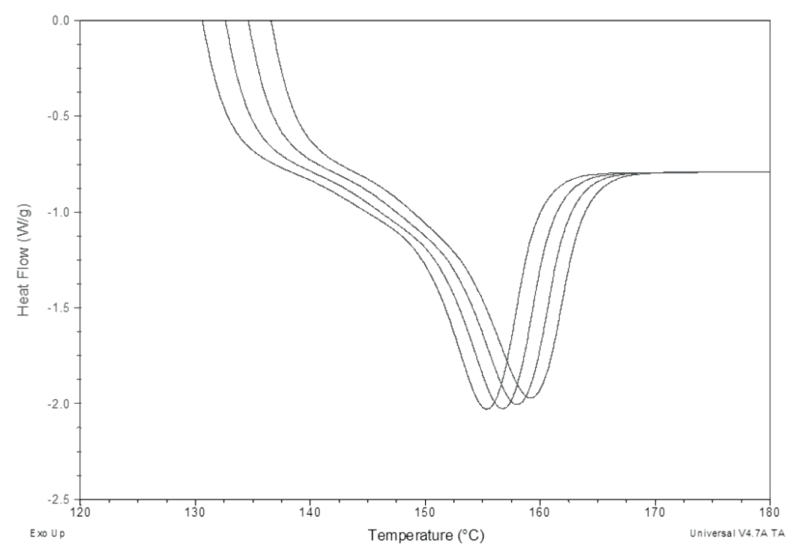

Figure 6 Changing of the melting peak temperatures

be change from 2 dimension to 3 , but the transformation is not complete. The activation energy was calculated from the

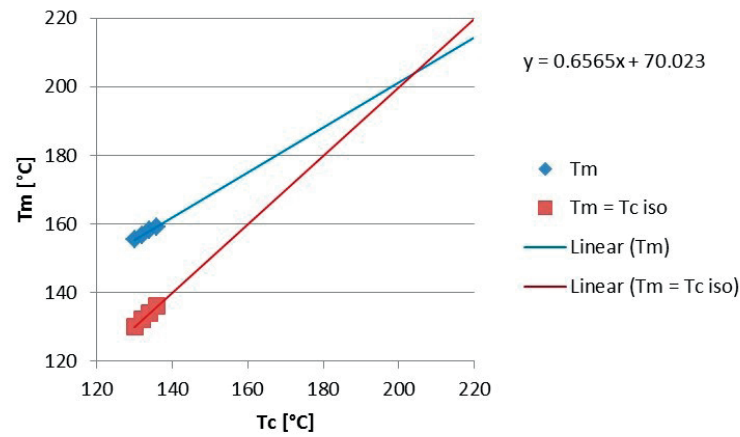

Figure 7 Determination of the equilibrium melting temperature

change of rate constant by the Arrhenius equation. Finally, the equilibrium melting temperature was determined from the melting temperature by the Hoffman-Weeks linear method. These results are the basis for further experiments, like nucleation to improve crystallization and provide better mechanical properties for the 3D printing model.

\section{Acknowledgement}

This research is supported by EFOP-3.6.1-16-2016-00014 project. The Project is supported by the Hungarian Government and co-financed by the European Social Fund.

I would like to thank Prof. Karoly Belina for invaluable help in acquiring thermal analysis and Balazs Polgar for providing the PLA filament.

\section{References}

[1] GURR, M., MULHAUPT, R.: Rapid Prototyping. Hashmi, S. (Ed.): Reference Module in Material Science and Material Engineering, Elsevier, 2016.

[2] MURARIU, M., DUBOIS, P.: PLA Composites: From Production to Properties. Advanced Drug Delivery Reviews, 107, 17-46, 2016.

[3] LIM, L. - T., AURAS, R., RUBINO, M.: Processing Technologies for Poly (lactic-acid). Progress in Polymer Science, 33, 820-852, 2008.

[4] SAEIDLOU, S., HUNEAULT, M. A., LI, H., PARK, C. B.: Poly (lactic acid) Crystallization. Progress in Polymer Science, $37,16657-$ 1677, 2012.

[5] EHRENSTEIN, G. W., RIEDEL, G., TRAWIEL, P.: Thermal Analysis of Plastics Theory and Practice. Hanser Publishers, Munich, Cincinnati, 2004.

[6] BELINA, K., HALASZ, L., VORSTER, O. C., JUHASZ, P.: Crystallization Properties of $\alpha$ - Olefin Homo- and Copolymers/ $\alpha$ - Olefin Homo/es Kopolimerek Kristalyosodasi Tulajdonsagai (in Hungarian). Plastics and Rubber/Muanyag es Gumi, $43(8), 347$. 356, 2006.

[7] BELINA, K., POSA, M., KECSKES, B.: Melting and Crystallization Behavior of Oriented Polyamide Copolymer/Orientalt Poliamid Kopolimer Olvadasi es Kristalyosodasi Jellemzoi (in Hungarian). Plastics and Rubber/Muanyag es Gumi, 46(5), 147-176, 2009.

[8] LEE, S. W., CAKMAK, M.: Growth Habits and Kinetics of Crystallization of Poly (Ethylene 2.6 - Naphthalate) under Isothermal and Nonisothermal Conditions. Journal of Macromolecular Science, Part B, 37:4, 501-526, 1998. 
[9] PUKANSZKY, B., VARGA, J.: Introduction to Physics of Plastics/Bevezetes a Muanyagok Fizikajaba, (in Hungarian). Published by Budapest University of Technology and Economics, Department of Physical Chemistry and Materials Science, Plastic and Rubber Industry Laboratory/Kiadja a BME Fizikai Kemia es Anyagtudomanyi Tanszek, Muanyag es Gumiipari Laboratorium, Budapest, 2012. 